Pragmatic Case Studies in Psychotherapy, http://pcsp.libraries.rutgers.edu

Volume 4, Module 1, Article 1, pp. 1- 24, 02-11-08 [copyright by author]

ACTION EDITOR'S NOTE FOR VOLUME 4, MODULE 1 (Ronald B. Miller, St. Michael's College, Colchester, Vermont, Associate Editor, PCSP): In the mid 1980's, I happened upon a short article in the bulletin of Division 29 of the American Psychological Association in which Dr. Bertram Karon claimed that psychotherapy was "the treatment of choice" in schizophrenic disorders, and that he had in fact for over 25 years been practicing psychodynamic psychotherapy with schizophrenic patients, often successfully. The claim went against everything I had learned in my doctoral education in clinical psychology or read over the previous 15 years in the mainstream psychological and psychiatric literature, but it was presented clearly and cogently with supporting empirical evidence.

I resolved to find out more about this intriguing and controversial assertion, and ultimately in 1987 arranged for Dr. Karon to give a workshop on the psychotherapy of schizophrenia in the graduate program where I teach (Saint Michael's College). This was the first of a series of presentations I have heard Dr. Karon give over the past 20 years, and have always found his lectures and workshops intellectually vibrant, clinically inspiring and highly pragmatic. Having also become familiar with his writing, I realized that much of the compelling case material that he had presented in vignette form in lectures and workshops had not been published as comprehensive case studies. With this in mind, I invited Dr. Karon to submit a case study illustrating his approach to psychotherapy with schizophrenic disorders.

It should be noted at the outset that Dr. Karon's presentation in his case study is unconventional in two ways. First, Dr. Karon's approach to the case seems to violate a number of established assumptions about the psychological treatment of schizophrenics, e.g., (a) that detailed diagnosis is necessary, (b) that medication is a crucial tool in treatment, (c) that psychoanalytic therapy is of questionable value in treatment, (d) that psychiatrists should be viewed as close collaborators in any treatment, and (e) that the psychodynamic therapist should maintain technical neutrality, not being too directive in the patient's life. In his case study, Dr. Karon provides a rationale as to why he questions all these assumptions. Second, Dr. Karon does not hesitate to also address the social, professional, and moral consequences for the patient and therapist of both following, and departing from, these traditional assumptions. This places his work in the broad tradition of others like H. S. Sullivan, Frieda FrommReichmann, Thomas Szasz, R.D. Laing, and Loren Mosher who have challenged the prevailing cultural and professional norms about the meaning of schizophrenic symptoms and our societal response to them. One can not meaningfully address these issues without entering into the broader discussion of the politics of therapy, which Dr. Karon does explicitly, while at the same time providing pragmatic instruction as to how one does the clinical work from this alternative perspective, and empirical research results that back-up his claims. Because of the unconventional aspects of Dr. Karon's case study, we have invited Commentators who both critique (Davidson) and support (VandenBos and Silver) these components of Karon's innovative and challenging case study.

\title{
An "Incurable" Schizophrenic: The Case of Mr. X
}

\section{BERTRAM P. KARON ${ }^{\text {a,b,c }}$}

\footnotetext{
a Michigan State University and the Michigan Psychoanalytic Council

${ }^{\mathrm{b}}$ Correspondence concerning this article should be addressed to Bertram P. Karon, Department of Psychology, Michigan State University, East Lansing, MI 48824

${ }^{\mathrm{c}}$ I wish to express my thanks for editorial assistance to Anmarie J. Widener, M.A., M.S.W
}

ABSTRACT
Mr. X, a schizophrenic, was evaluated by all his psychiatrists as "incurable” after several years of
unsuccessful outpatient and two months of inpatient treatment, both with medications. Electro-convulsive
therapy (ECT) was strongly but pessimistically recommended. He was not eating, not sleeping, and
continuously hallucinating. He began outpatient psychoanalytic therapy. All medications were stopped.
After three days he began eating. After four months he began working at an intellectually demanding job.


After two years he could be assured that he would never be psychotic again under normal stresses. But that was not good enough for him. He kept raising new issues: problems in living, difficulties writing his first book, psychosomatic problems, problems in enjoying ordinary pleasures, marital problems, undoing problems he had caused his son. The total treatment took 14 years. More than 20 years after the completion of treatment the patient sent a note indicating his continued professional accomplishments and thanking the therapist for "giving me my life back."

Key words: schizophrenia, psychoanalytic therapy

\section{CASE CONTEXT AND METHOD}

In this era most mental health professionals do not know that any schizophrenic ever got better with psychotherapy. Of course, there are a group of professionals, members of "ISPS" (the International Society for the Psychological Treatments of Schizophrenia and Other Psychoses, originally named the International Symposium for the Psychotherapy of Schizophrenia) and its American chapter, ISPS-US, most of whom are familiar with successfully treated cases (ISPS, 2006).

There are also the books - e.g., Greenberg's (1964), I Never Promised You a Rose Garden; Strean and Freeman's (1990), The Severed Soul; and Dorman's (2003), Dante's Cure all of which describe successful treatments, along with the special issue of the Journal of the American Academy of Psychoanalysis and Dynamic Psychiatry (Silver \& Larsen, 2003), which is comprised of articles concerning the clinical experience and research evidence for the effectiveness of psychotherapy for persons with schizophrenia.

Nonetheless, it is useful to describe the treatment of an individual who was declared "hopeless" by all his treating psychiatrists, but who recovered with psychoanalytic therapy and went on to a successful life as a creative professional and a good husband and father. The patient, who has told colleagues and students that he once was schizophrenic, has given me permission to share his experience if it might lead others to appropriate treatment. He himself has been described by students as telling them that you don't deserve to hurt that much, and there are people out there who can help you. "I know. I really know. I was schizophrenic, and if I could get help, you can get help.” They have found it hard to believe he was ever schizophrenic, but he assured them it was true, and that if he could get help, they can get help; and he advised them to seek out psychotherapy, for which they were later grateful.

In 1963 a graduate student in experimental psychology asked me about a friend of his, a young faculty member in another department, whom I shall call Mr. X, who was hospitalized as schizophrenic. The graduate student had heard me give a colloquium on treating persons with schizophrenia with psychoanalytic therapy and wanted to know if there was there any hope for his friend. I said he needed psychoanalytic therapy, and that, if he received it, he would probably get better, and that under no conditions to permit electro-convulsive treatment (ECT), a treatment this patient's family was considering. 
Of course, by that time I had completed a psychology internship at an institution that specialized in treating with psychoanalytic therapy chronic schizophrenics who had previously failed to respond to treatment at the most prestigious and expensive psychiatric hospitals in the United States. While outcomes at that institution varied with the therapist, my experiences were sufficiently impressive that they led to a series of papers about the psychoanalytic therapy of schizophrenia (Karon, 1958; Karon \& Rosberg, 1958; Rosberg \& Karon, 1958, 1959).

Subsequently, I worked as the Chief Psychologist at the minimum security reformatory for male adolescents for an Eastern state (there was also a medium security reformatory), which gave me experience with acute patients. I had also completed a post-doctoral research fellowhip at a psychiatric hospital that practiced psychoanalytic therapy (although not usually with schizophrenics or seriously depressed individuals unless they were also given medication or ECT), supportive therapy, medication, and electro-shock treatment, so that I had ample observations of the effects of all these treatments, alone and in combination, and had treated patients in private practice including persons with schizophrenia, before taking an academic position in 1962.

All of these clinical experiences led to the paper on treating acute schizophrenics (Karon, 1965), which said that the treatment of choice was psychoanalytic therapy as opposed to both electric shock treatment or medication. Schizophrenia was described as a chronic terror syndrome based on the whole life history, starting in early infancy, as experienced by the patient and on the fantasies, conscious and conscious, formed on the basis of actual experiences and earlier fantasies, with which that life was given meaning. Specific psychotherapeutic procedures were recommended, and illustrative case material included. These views were later clarified and expanded in the book, Psychotherapy of Schizophrenia: The Treatment of Choice (Karon \& VandenBos, 1981), along with relevant outcome research.

"Can his wife call you?" asked the graduate student. (The specific statements quoted in this paper were, of course, never transcribed or recorded, but were so clear or dramatic that they are easy to remember. However, since they are the products of memory it is possible that they are not accurate, but represent words with essentially the same meanings.)

\section{"Of course."}

The wife called me and told me that he had seen someone in a Northeastern city for therapy and medication for several years, and when he came here (a Midwestern state) he received medication and psychotherapy on an outpatient basis for roughly a year from a psychiatrist with a very good local reputation. The patient had deteriorated, and the medication increased until he was finally hospitalized. Despite increased and combined medications, he had continued to deteriorate even more, and the patient's wife was told he was an "incurable schizophrenic" by both his outpatient psychiatrist and by a consensus of the inpatient psychiatric staff. His only hope, she was told, was electro-convulsive therapy, which probably would not cure him, but it was the only hope he had.

The patient's wife, on my advice, withdrew her permission for electro-convulsive therapy, which was scheduled for the next morning. I asked colleagues about the hospital and was told that it was one which emphasized ECT. Also on my advice, she withdrew him from the 
hospital, despite the staff's objections. She was told that she was killing him by not permitting ECT. They refused to tell her what medications he was on, but when she had him leave the hospital anyway, they relented and told her what the medications were. She brought him to my office immediately upon discharge. He was not eating, he was not sleeping, he had trouble standing, and he was continuously hallucinating. We began psychotherapy immediately, and later continued while the client lived at home. The patient was not violent, but he was scared. During the first month or two, his wife and friends took turns staying with him. After that it was not necessary.

At that time I did not have a cooperating hospital. Relations between psychologists and psychiatrists were so bad that less than two years before I started working with this patient, the County Medical Society had declared that it was unethical for a physician to refer a patient to a psychologist. Complaints from psychiatrists to the Governor and the President of the University that private practice by University psychologists was socialized medicine had led to a ban on the use of Psychology Department offices for private practice. All of this was just before I came to this area.

The therapy was carried out in an outpatient office, except for a few sessions at an all-night restaurant as described below, with his wife accompanying him to the office during the early part of the therapy when he was not yet able to drive, but not participating after the first hour. As is my usual practice, she also had one confidential hour with me, and the right to call me at any time thereafter, but our conversations after that first hour were always to be described to the patient.

The patient, too, had the right to telephone me at any time. If he did not reach me, he was to phone an hour later. If that did not reach me, phone an hour later. He was to continue until he reached me. He was told that even if it was two in the morning, he knew that I had been home less than an hour, so he was not disturbing me. It is very reassuring for a patient to know they can reach their therapist by phone if necessary, and very few patients abuse that privilege. In Mr. $\mathrm{X}$ 's case it helped him pull out of very disturbing experiences.

This was many years ago, and it is, of course, difficult to remember the details of each session. In my experience, much of every session makes no sense to me, or is repetitive; and what I remember is when things coalesce and become clear. But the reader should remember that every therapy hour is full of detail and confusion and repetitiveness, whose feel does not come through in concise case summaries.

The therapist must create a therapeutic alliance by becoming unequivocally helpful, tolerating incoherence, tolerating not understanding, and being realistically optimistic. The patient is usually surprised that you expect them to get better, with hard work. They do not believe you, because most of them have been told by professionals that they have a genetic disease whose biological defect is known and which is incurable. With the best of modern treatment, by which the professionals mean medication, they can be tolerable to other people most of the time. In other words the aim of treatment is to help them become tolerable invalids.

But these premises are wrong. The genetic evidence is very weak. At most it suggests a possible (but not clearly demonstrated) increased vulnerability to bad experiences. There are no 
replicated biological findings except for those which occur in anyone suffering terror and those which have been demonstrated to be the result of the medications (and/or ECT). Much of this research is briefly summarized in Karon (2003) and, in more detail, in Read, Mosher, \& Bentall (2004).

The therapist must give a feeling of strength in the sense that you are willing and able to deal with anything and go anywhere the patient needs to go, no matter how scary. If you know things that will help the patient with the patient's current concerns (not yours), you let them know. The patient is often surprised that you have anything to offer that actually helps, that you care about what they are afraid of, and that you listen carefully and take seriously what they say. Unlike working with neurotics, the therapist for a psychotic must avoid being ambiguous. Ambiguity is experienced by the patient as the therapist being a monster, because the ambiguity is filled by the patient with negative transferences. As with any person transference experiences always seem like realistic perceptions. It helps to sit where the patient can see you, and to try to be helpful, not neutral. It is also helpful to talk freely if you have something to say that you think might be helpful to the patient at that moment.

Typically, psychotic patients do not trust you. You cannot expect a psychotic patient to tell you everything they understand. They are afraid that anything they tell you might be used to hurt them. That is why it is essential to tolerate not understanding as well as to try to be c helpful.

Psychoanalytic ideas often suggest meaning in the midst of the chaos, which often gives the therapist a helpful first approximation, but one with large gaps and places where it seems to contradict itself. Then we can listen around the gaps and contradictions The therapist deals with what he or she can understand, corrects his own misunderstandings, pays careful attention to what is going on, with the certainty that eventually it will all make sense, and when it does, the patient will get better. Even grossly incoherent patients will sometimes say important things clearly in the midst of their incoherent verbalizations, which they do not expect the therapist to notice or take seriously. (The unconscious meaning of this is probably the patient's wish that the therapist will treat it as nonsense, so that the patient does not have to deal with the anxiety of thinking about it seriously, or the patient's wish that the therapist will confirm earlier experiences with a parent or previous professional, or both, that neither the patient's real feelings nor their observations of bad things should be taken seriously.) As you deal with those fragments that make sense, more and more of what the patient says makes more sense. Of course, this is easier if you have seen similar patients get better with psychotherapy, or have a supervisor who has seen patients get better with therapy. The patient, of course, does not have any reason to be optimistic or to trust the therapist. The difficulty of staying with each session, understanding fragments, and dealing with those fragments, and being stubbornly helpful, even when things do not seem to make sense and the patient does not seem to be responding, cannot come through in a brief summary such as this. Perhaps the best easily available sample of what it is like when I work with a severely disturbed patient is the training video I made for the American Psychological Association (Karon, 1994). Also helpful in its more detailed description of technique is Karon and VandenBos (1981).

Following Freud's advice on technique, I do not use process notes. I do make some notes in the first session and once in a while if I think it will be helpful. Freud felt that taking notes 
after the hour was better than taking notes during the hour, because you do not listen as carefully when you take notes. Not taking notes at all is even better, because your thoughts tend to stick to your notes, and you are not as sensitive to new material. Of course, if there was something complicated that you were concerned you might forget, Freud recommended that you write it down. None of his technical recommendations were ever rigid. (He made a point of saying his technical recommendations were "recommendations" which usually help, but which you will change if they don’t help, rather than "rules,” which are things you always do.)

I did not check this patient's treatment with any other professionals, except for two instances late in treatment described below. Given the relationship between psychiatrists and psychologists in that area at that time, it would have been at best fruitless and at worst provocative to discuss his treatment or ask for records from his outpatient psychiatrist or his hospital. The important thing was to help him, and he and his wife were very good informants. Moreover, the University and the University town are really small communities, and from time to time during and after his treatment I heard about him from students, faculty, and community people who did not know he was a patient of mine. Even my son and his son were friends in high school. (Of course, both of them knew that he had been a patient of mine, but did not know the details of his treatment.)

It is interesting that despite my clear description of the patient's experience of treatment by psychiatrists, a reviewer of this paper asked why I did not work with psychiatrists. To do so in that city at that time, of course, would have condemned the patient to a course of ECT, a treatment that would have done the patient more harm than good. But, of course, what the reviewer might really have meant was why did I not use medication.

In this case one did not have to be theoretical. Medication had been tried and found wanting. That is why his treating psychiatrists were insisting on ECT. However, my clinical experience as well as the findings of my later research (Karon \& VandenBos, 1981) indicated that the optimal treatment was psychoanalytic therapy with a competent therapist without medication if the therapist, the patient, and the setting (e.g., hospital, family, etc.) can tolerate it. Temporary medication accompanying psychoanalytic therapy is the next best option.

In the years since I began treating Mr. X, I have developed good working relationships with a number of psychoanalytic psychiatrists, not only as supervisors and as supervisees, but as mutually respecting colleagues. Some of them use medication more than I do. But typical was Thomas Tierney, M.D., in the Michigan State Psychotherapy Project described below, who did not like working with disorganized patients, so he always started them on medication. He told the patients that the medication did not cure anything; it only made things tolerable so they could talk. The only thing that would cure them, he said, was their understanding. He then withdrew them from medication as rapidly as he felt they cold tolerate. Empirically, this turned out to be a very good way to work. All of this is discussed below.

Two University Deans contacted me about Mr.X during the early months of his treatment. One wanted to know whether there was anything the Dean might do to help. I suggested he call the patient, ask him that question, and take seriously anything the patient said. 
The other, Dean of his College, wanted to know when the patient might be ready to go back to work. I told the Dean I would think about it, and get back to him. When I told the patient about the conversation (as I did with any conversation about him with anyone) and asked him, he said, "Not next term. Maybe the term after." I then called the Dean and said, "In my best clinical judgment, he won't be ready to go to work next term, but probably the term after."

In the first hour when I asked the patient what he wanted help with, he said, "I don't want to have this scared feeling, can't hold up straight. I don't know what it means, to have tension in the head. I don't want to have to hang around my wife's apron strings. I can't leave her by a foot. I don't want to be nauseating when my wife steps out of the room." (I made a note of this initial statement, which is why I can recall it verbatim.)

At some time in the first session, as I often do with patients who are feeling terrified, I said I would not kill him or let anyone else kill him. This is based on an observation by Bruno Bettelheim (in a 1954 colloquium at Princeton University) that every first psychotic episode is accompanied by an acute conscious fear of dying. In fact, in my experience, most schizophrenics are consciously aware of such a fear. This patient neither acted as if that were very helpful nor as if it were strange. Probably he did not believe me, but he did not say so.

\section{THE CLIENT}

Mr. X was from a middle-class family and had considered himself lucky to have such good parents, particularly such a good mother. However, even before this first psychotic break at the age of 31, he could not remember his childhood before the second year of high school, although he had never considered that to be abnormal.

Mr. X. was raised as a Jew, but was not religious as an adult. He had a brother three years older than he. His father had been given a course of ECT treatment for depression some years earlier, and had not held a job since. His mother still worked. Neither one of his parents had gone to college, but both he and his brother had. His brother was in business for himself. The patient had gone to a more reputable college than his brother and had earned a Ph.D. Shortly thereafter, the patient's problems seemed to get worse and worse.

\section{GUIDING CONCEPTION WITH RESEARCH AND CLINICAL EXPERIENCE SUPPORT}

The model used is psychoanalytic and is described in Karon and VandenBos (1981). A briefer and more recent description with later research can be found in Karon (2003). Schizophrenia is conceptualized as a chronic terror syndrome. All of the symptoms of schizophrenia may be understood as manifestations of terror or defenses against terror. I have never treated a schizophrenic patient whose life history, as experienced by the patient, would not have driven me psychotic, and with the same symptoms.

When the patient's life as given meaning by his or her conscious and unconscious fantasies seems to mean that they are about to be annihilated, they go psychotic. Fantasies are 
formed on the basis of real experiences and pre-existing fantasies, so that all of life, from early infancy onward, is relevant. Usually something happens early which changes subsequent fantasies, which change how subsequent events are experienced, which again change the fantasies, and so on.

All of us have the potential for schizophrenic symptoms if life becomes bad enough. Luckily, most of us will never have to develop psychotic symptoms. While there are adult experiences that are sufficiently horrible to produce schizophrenic symptoms in basically healthy people, most people who become schizophrenic have had a series of subtle and unsubtle bad experiences which have made them vulnerable. To discover the traumas, it helps to get a case history. John Reid and his colleagues (Read \& Ross, 2003; Read, Goodman, Morrison, Ross, \& Aderhold, 2004; Read, Seymour, \& Mosher, 2004.) have documented how the case records, even in hospitals whose staff believe that life experiences have nothing to with schizophrenia, reveal a dramatic increase in the incidence of obvious physical and/or sexual abuse for schizophrenic patients. The increase is even more dramatic if you specifically interview the patients. Of course, the most accurate and detailed account of the traumas experienced by each patient comes from the material described or enacted in therapy. However, it may take considerable work before the patient's life becomes clear.

Early in my career I was taught to dismiss schizophrenic patients' unusual or unusually severe experiences as psychotic delusions. But my clinical experience is that the severe traumas, even seemingly improbable ones, are usually true. Sometimes the initial description is distorted (if not completely repressed). But even distorted memories are related to the real problems. As they are discussed in therapy, they become more accurate. Patients who recover repressed or distorted memories almost always try to check on their accuracy, if it is possible and safe to do so. In my experience, when the details become consistent, and consistent with the other material, and the patient improves, the reconstruction is almost always confirmed as accurate, if information is available from reliable outside sources such as family members or newspaper reports.

People with schizophrenia are highly varied, aside from their symptoms. Their life histories and specific traumas are equally varied. There are patients whose traumas have nothing to do with their parents. But for most patients as for most people, their relationships with their parents are complexly related to their strengths and weaknesses. There are obviously abusive and hurtful parents, but they are a minority. Most parents of schizophrenic patients are good people who would not consciously do anything to injure their child. Often they will go to great lengths to attempt to get help for their child. Sometimes they do hurtful things because they mistakenly believe that their hurtful actions are good for their child. Unfortunately, to understand traumatic parenting completely, it is also necessary to take into account unconscious processes (Karon \& Widener, 1994; Karon, in press). Many parents of schizophrenics suffer from unconscious problems, based on their own life history, which can be measured from the Thematic Apperception Test, and which have been shown in a series of studies to make their children vulnerable (Karon, in press). They are not culpable, any more than their children are for hallucinating, or anyone else is for any other unconsciously caused symptom. Unfortunately, unconscious problems cannot be changed until they are thought about consciously. 
The thought disorder (the inability to think rationally when you want to) in persons with schizophrenia varies with the degree of conscious terror and with the adequacy of the patient's defenses at a given time. There is no general schizophrenic language, but each patient has a language that the therapist must learn.

The apparently weak affect, in schizophrenic patients, is usually a chronic terror state in which lesser affects are blanched out by terror. Apparently inappropriate affects are usually socially inappropriate, but not inappropriate to the patient's inner life.

Catatonic symptoms are simply a specific chronic terror state. According to FrommReichmann (1947), the patients see and hear everything that is going on, but feel as if they will die if they move. Ratner's biological research (Ratner, Karon, VandenBos,\& Denny, 1981) showed that the catatonic state has developed in evolution as the last stage of defense of a prey in the clutch of a predator. In that state, while fully conscious, the animal does not seem to react to even intense pain, and the predator acts as if the animal is already dead.

Hallucinations are waking dreams, understandable and treatable using Freud's theory of dreams, with minor modifications.

Delusions have four primary bases:

1) Transference to the world at large.

2) Defense against pseudo-homosexual anxieties, as described by Freud.

3) Peculiar concepts or meanings to concepts taught within a specific family.

4) The need to have a more or less systematic understanding of our selves and our world, even if we have strange experiences. (Patients have strange experiences, both because of their symptoms but also frequently because of unusual real experiences.)

The therapist must help the patient create a livable world. As in any therapy creating a therapeutic alliance is essential; but with psychotic patients it is more difficult and it forms a more persistent part of the therapist's work.

The severity of the symptoms generally means there are more bad things to transfer, and hence the transference to the therapist will tend to be negative. When there is ambiguity, and sometimes even when there is not, the therapist may be perceived as hostile, dangerous, shaming, belittling, and/or conspiring against the patient. This makes the therapeutic alliance harder to create and maintain. The therapist should try to be unambiguously helpful; the blank screen will inevitably become a monster. Frequently the patients do not communicate even what they already understand, because they do not trust you. It is important to tolerate not understanding; the moment you decide you will not abandon the patient just because you do not understand or the material is painful or the patient is hostile, you are already being helpful.

As in any therapy, what changes the patient is the internalization of the therapist as well as the insights gained. The patient internalizes the therapist into the superego, so that the patient treats him or herself in the kindly, rational way the therapist would instead of the rigid, punitive way that most patients treat themselves (based on their early identifications). The patient 
internalizes the therapist into the ego as a model for how a human being might be, discarding those quirks of the therapist which are not useful. The patient internalizes the therapy relationship as a model of what a human relationship might be. The process of internalization is central to effective therapy, particularly with psychotic patients, but it goes on without explicit attention as an automatic part of the patient-therapist interaction.

The therapist must repeatedly distinguish between thoughts and feelings versus actions. All thoughts and feelings are permissible; and actions can best be controlled if the patient dares to allow him or herself freedom of feeling and of thought.

The role of insight is the same as in any psychoanalytic therapy: making the unconscious conscious, changing the defenses in part by awareness, making the connection between the past and the present. Understanding the transference is central. The more severely disturbed the patient, the more obvious the transference reaction. Schizophrenics are constantly trying to solve their problems, but they are too frightened to deal with the real problems directly; they deal with symbols. Only when the symbolic act (or symptom) and the original traumatic experience are reconnected in consciousness can the person overcome it.

When in doubt material is related by the therapist as probably concerning the mother because mothers are more important for both good and bad effects for most children than anyone else. And in early childhood, mothers seem so powerful that every experience is believed by the child to be her fault, whether or not that is objectively true.

A reviewer of this paper characterized the therapy as interpersonal and wondered why ego psychological concepts were not used, particularly emphasizing a defect in the infant rather than mothering and other experiences. Such a view is not a necessity of ego psychology. The theory above is not theoretically pure (very few good therapists are), but is primarily derived from ego psychology, as understood by Sigmund Freud, Anna Freud, Erik Erikson, Richard and Editha Sterba, and Bruno Bettelheim; interpersonal theory, as understood by Harry Stack Sullivan and Freida Fromm-Reichmann; object relations theory, as understood by Ronald Fairbairn and Harry Guntrip; and affect theory, as understood by Silvan Tomkins, and modified on the basis of clinical experience. As for emphasizing a defect in the infant, that is a view that prepares the patient for a life time as an invalid and the therapist for accepting therapeutic failures. There is a defect, descriptively, but it is best understood as the result of experience (including fantasies), which gets better when understood. I have never treated a schizophrenic whose life would not have made me schizophrenic. But it is often difficult to discover what that life really was.

Belief in a defect in the infant which has to be lived with rather than understood may be a way of trying to help parents not feel guilty about the possibility that they made hurtful mistakes in raising their children or it may be a belief based on the secondary accounts (which are often more impressive than the original studies) of the evidence for possible genetic factors. A recent brief, but scientifically accurate, review of the actual evidence (and their weakness) on genetic factors may be found in Joseph (2004). 
Of course, belief in a defect in the infant may be a psychoanalytically phrased justification for medication. But clinical experience as well as the research evidence is that while psychoanalytic therapy accompanied by medication may often be the fastest way to improve behavioral control, faster than either medication or therapy alone, there is a price to be paid. Psychoanalytic therapy is much more effective than medication in the long run, and the most striking advantage is the improvement in the thought disorder, the ability to think logically when you want to. But continued accompanying medication decreases the improvement in the thought disorder. When we discovered this in the Michigan Psychotherapy Research project, described below, we thought this was probably due to the fact that all antipsychotic medications decrease emotions, including terror, which is probably the basis of their therapeutic effect. But affects within the therapy hour are also one of the curative factors in psychotherapy (not the only one, of course). Since then, however, there has been increasing evidence that antipsychotic medications are also neurotoxic (e.g., Jackson, 2005). Robert Whitaker (2002) has summarized the evidence that countries that cannot afford to medicate within five years have many more longterm recoveries and far fewer chronically disabled schizophrenics than countries where nearly every patient is medicated. Also, Deikman and L. Whitaker (1979) demonstrated that a ward where no psychotic patients were medicated, but every crisis was handled psychotherapeutically, had fewer suicide attempts, fewer suicides, fewer runaways, and a lower rehospitalization rate than a comparison ward with expert psychopharmacology, more staff, and a policy of transferring their most difficult patients to the state hospital. (The psychotherapeutic ward did not transfer any patients, but treated them all.)

Empirical data to support the effectiveness of the specific psychoanalytic guiding conception presented above and employed in the case can be found in the Michigan State Psychotherapy Project (Karon \& Vandenbos, 1972; Karon \& VandenBos, 1981). This project consisted of a randomized, controlled study of 36 schizophrenics, 16 to 49 years old, who were randomly assigned to three treatment groups: psychoanalytic therapy alone, psychoanalytic therapy with medication, and medication alone. Using masked evaluations, patients were examined before treatment, and after 6, 12, and 20 months of treatment, with the Rorschach, the Thematic Apperception Test (TAT), a clinical status interview, and a battery of intellectual tests, e.g., the Thorndike-Gallup Vocabulary Test, Porteus Mazes, WAIS, and the Feldman-Drasgow Visual-Verbal Test. Measures of psychotherapy effectiveness were divided into four groups: length of hospitalization, including a two-year-after treatment follow-up; clinical evaluation of functioning; direct measures of the thought disorder; and projective tests. Overall, the results indicated that 70 sessions of psychoanalytic therapy over a 20 month period was significantly more helpful than medication; psychotherapy plus medication was more helpful than medication alone, but not as helpful as psychotherapy alone, or psychotherapy accompanied by initial medication which was withdrawn as rapidly as the patient could tolerate. The most striking advantage of psychotherapy over medication was the improvement in the thought disorder, which was the outcome variable most predictive of not needing to be rehospitalized in the follow-up period. But continuing maintenance medication accompanying the psychoanalytic therapy decreased the improvement in the thought disorder with psychotherapy as compared to medication without psychotherapy, and also decreased the advantage of psychotherapy with respect to rehospitalization in the follow-up period. 
Consequently, it is my current view that the optimal treatment is psychoanalytic therapy with a competent therapist without medication. Psychotherapy with initial medication which is withdrawn as rapidly as the patient can tolerate is nearly as good. Of course, medication can be used to cope with a crisis (although I find it preferable to deal with it psychotherapeutically, if possible), and I never require a patient to give up medication he or she feels they need or want (which is rarely the case), and I tell them that. However, eventually all my patients choose to go off medication. Recent evidence shows that the strong withdrawal reactions of most antipsychotic medications require careful attention (Breggin \& Cohen, 1999) and usually gradual withdrawal, although that was not what was done in this case. However, I met with this patient every day during the first week without either hospitalization or medication, and six days in the second week, and five days thereafter, so that I was there while he coped with any withdrawalbased increase in symptoms.

\section{ASSESSMENT OF THE CLIENT'S PROBLEMS, GOALS, STRENGTHS, AND HISTORY}

At the beginning of treatment, Mr. X was psychotic and largely incoherent, and he had no memory of anything before high school, even before his psychotic break. The material about his history emerged during the therapy sessions, and will be described in section 6 below. What was known about Mr. X at the beginning of treatment was captured, after about three weeks of therapy, when Mr. X. was somewhat more coherent, by Roberta Vogel, then a graduate student, who tested him using the Rorschach, TAT, and Draw-a-Person procedures. Her report read:

Mr. X shows extreme feelings of inadequacy, guilt, and worthlessness. He puts great value on intellectual competence and achievements and is often severely critical of himself and others in this regard. He does show a lot of inner intellectual resources upon which to fall back if the emotionally crippling factors could be lessened or eliminated. His extreme over-intellectual approach to the environment prevents him from taking into account the more practical aspects of life. He probably tended to detachedly intellectualize his difficulties previously thus preventing free emotional expression and outlet for his feelings and causing a damming-up which gave way.

Presently, he shows extreme fear over sexuality, feeling guilty for having such impulses and showing a need for punishment for this. He shows the greatest fear of being castrated by his mother, whom he sees as being resentful and jealous of his masculinity. He further feels guilt and ambivalence over his dependency upon women, although, in the case of his mother, he feels this is generally what is expected of him. However, he continually confuses this dependency with sexuality and sees his mother and most women as demanding a sexual kind of submission by him ( giving up his penis to them). He is presently unable to separate these two things: sex and dependency.

Thus, there is an approach-avoidant conflict with regard to the maternal type love he receives from his wife, who in his mind tends to be confused at times with his mother. He sees his wife as being jealous of his achievements, also, and for him being adequate is associated with sexuality and masculinity. Though he has strong underlying feelings of anger and hate toward these women, he is unable to express these overtly due to his fear of his mother whom he sees as domineering and omnipotent, capable of bringing down upon him severe punishments (castration) for his "sins" (sexual feelings - masculinity -- adequacy). 
This undoubtedly is connected with this inability to carry out his academic duties, i.e., being an adequate person, because of all the associations tied up with this, i.e., being a man, having sexual feelings.

He is continually plagued by these ambivalent feelings which are present in consciousness and which he does not know how to handle -- the need for love and nurturance, yet a need to be strong and independent; the extreme dependency upon women and the extreme hate he cannot express; the fear of punishment for his sexual feelings which he cannot now easily deny. These inner conflicts prohibit him from performing tasks which seem routine to most but which for him are very difficult because of their connection to the above mentioned conflicts.

At present he is in a battle for his own survival as a person. At the same time he is trying to refrain from rebellion against the controlling figures in his life, another part of him wants so desperately to be rid of this control. He feels he is not strong enough to do this alone and would be inclined to give up in defeat. At the present time, he feels he is fighting a losing battle; he needs very strong support and the reassurance that there will be no impending doom if he gives vent to his inner needs. Without this support, he could easily slip into a world where reality is completely lost.

At this time, suicidal acting out seems contra-indicated for he still feels too incapacitated by these inner conflicts to take such decisive action. However, he would bear watching when he begins to emerge from his present state of emotional turmoil and begins to improve, for then the angry feelings he has may start pressing for overt expression and if he is at that time still unable to direct outward, the full force of them would be directed as usual upon himself. If he can be persuaded of the futility of such an act, a later threat of suicide will not be present.

While the test report was remarkably accurate, it was not really of much help because one can only make use of what comes up in therapy. Luckily, most everything in it had come up. Of course, test reports are often very helpful in stalemated treatments when it is not clear why things are stalemated, or when suicide or homicidal danger are being sweated out.

The question has been raised whether the patient was not really a manic-depressive (or severe bi-polar) rather than schizophrenic. At the time of treatment, the diagnosis was not an issue, because his outpatient psychiatrist, the psychiatrists who examined him in the hospital, and a consensus of the psychiatrists on the hospital staff had all diagnosed him as schizophrenic, with no disagreements. Similarly, he fits the current clinical criteria, DSM-IV-TR (American Psychiatric Association, 2000) for schizophrenia rather than bi-polar disorders. From my clinical perspective, the patient was clearly schizophrenic: his material was primarily related to terror, not to depression nor to manic symptoms. (The diagnostic label was not emphasized in the testing report, because it was not an issue, and the diagnostician emphasized information that might be helpful in the treatment.)

It is interesting that when a schizophrenic patient recovers with psychotherapy, many professionals raise the issue of whether the patient was not really a manic-depressive, probably because manic-depressives are known sometimes to have spontaneous recoveries. In my experience, some of those same professionals would nonetheless warn a manic-depressive 
against undergoing psychotherapy and warn the patient that they are doomed unless they take medication for life. That the patient got better with psychotherapy without medication would then still have been an important finding. But this patient was schizophrenic. For discussions of the psychoanalytic treatment of manic-depressive patients without medication, see Teixeira (1992) and Karon (2005).

\title{
5. FORMULATION AND TREATMENT PLAN
}

Except for the formulation ideas implied in the just presented test report, an explicit case formulation was never a part of the treatment. A good therapist deals with what the patient brings up and where the patient is at that time. The therapist deals with the obvious problems. Thus, if the patient cannot eat that has a high priority because it can kill the patient. Each of the other symptoms and life problems are dealt with as they arise in the course of treatment. An early case formulation might be reassuring to record-keepers, but patients, particularly severely disturbed patients, rarely give an accurate description of their concerns early in treatment. Moreover, in treating the deeply disturbed, the most important problems change because the patient continues to make progress - thus, at the beginning of treatment this patient was not concerned with his difficulty in writing a book, in his third year of treatment he was.

The beauty of psychoanalytic therapy is its flexibility. At each stage, indeed in each session, the therapist deals with what seem most important at that moment, and can flexibly follow the patient into problems of any sort as they arise in the treatment.

Obviously, the patient was a severely schizophrenic individual with hallucinations and delusions who nonetheless had achieved a Ph.D level of education, a good work history, and a marriage before breaking down. He had been held together by the fantasy that if only he were good enough, then his parents would accept him. When that did not happen, his defenses unraveled. But even this was not clear to me until well into the treatment.

\section{A. COURSE OF THERAPY}

I immediately stopped all medications and started intensive psychoanalytic treatment - 7 days the first week; 6, the second; a 5-day-a-week schedule for several months; then a 4-sessionper-week regimen; and eventually, a regular 3-day-a-week schedule came to be our routine. After the third year, he was seen on a once per week basis. His wife and friends of the family took turns being with him for the first 2 months of treatment. Since not eating can kill you in 30 days, the treatment started with that symptom. The second session was at 7:00 a.m. at an allnight restaurant, the kind that looks like the men's room on the subway - all white tiles.

\author{
He said, "I can’t go in there. They'll think I’m crazy.” \\ “No,” I responded, “They’ll think you’re drunk.” \\ "I’ll throw up."
}

"Do you think you're the first drunk who threw up here tonight?” 
I discussed food, the fear of poisoning, and its possible origins while I ate. Most important is that his mother may have resented feeding him and, therefore, felt angry whenever she fed him, which hurts a child (Karon, 1960). This was interpreted symbolically: poison, after all, is simply something you eat and you get hurt afterwards. For a baby, an angry mother is like being hit with a sledge hammer. The patient reported nausea while watching me eat. But by the second restaurant session, he took some coffee for himself. Then coffee and toast at the third session. Finally, he ate breakfast, but he objected, "I'm paying for therapy and all I do is watch you eat. I've got a right to be listened to!” At that point, we returned to the office for more traditional treatment.

I allow family members, like spouses or parents, one confidential session; any other sessions, if they wish, or contacts would be discussed with the patient. I also make myself available to spouses or parents for advice. In my initial talks with his wife, she told me they had met when they were both on Fulbright scholarships to Paris. They began living together. I got the impression of two very anxious young people clinging to each other. She said he was the most interesting man she ever met. She had finished a Masters degree but stopped her education and was not currently working. She had grown up in the South and was, and felt she ought to be, a stay-at-home wife who was taking care of their five-year-old son. She did mention that their son was an accident.

The patient had first taken a job at a prestigious small college, but socializing with the members of his department and other faculty and administrators seemed to be a required part of the job, and he found it uncomfortable. Taking a job at a larger research university seemed to them as if they would have more choice about their private lives and more privacy. Nonetheless, things did not go well. I suggested that since he was incapacitated, she needed to resume working. This advice was helpful: she actually resented not working, but did not say so at the time because this was the early 1960's, and she felt obliged to be a traditional wife and mother. Nonetheless, she got a job teaching high school and eventually finished a Ph.D. and became a successful faculty member and assistant dean at a "Big Ten" research university. (It should be noted that she did go into psychoanalytic therapy herself before accomplishing these career moves.)

The details of Mr. X's life emerged in therapy, at first in fragments, later coherently. Mr. $\mathrm{X}$. described meeting his wife on the Fulbright in Paris. She was very bright and very attractive, but she was not Jewish. He had been told by someone she was "wild," but he did not know whether to believe it or not, and this still troubled him in the early years of the analysis. His mother literally told him, like the apocryphal Jewish mother stories, that he did not have to worry about the wedding because she would not be there. She would commit suicide. Right up to the day of the wedding, he was terrified that she would carry out her threat.

His previous experiences with women were not good. He both felt that he ought to be sexually active and attractive and, at the same time, any interest in sexuality or sexual activity was bad. He was intensely guilty about masturbating, feeling as many disturbed people do, that his body and his penis really did not belong to him. I told him that his parents were wrong, that his penis and his body belonged to him and that he had a right to enjoy them; his penis did not belong to his mother but to him. 
The year before he went to Paris, he had been seeing a woman seriously and they took a trip to Mexico together. She met another man on the trip and had sex with the new man in the room next to his in the motel where he could hear them. This was repeated on several nights. He described his feelings of humiliation and, with my help, rage.

At the beginning of treatment, he could not read, which is a serious problem for an academic, which needed to be helped before he could consider going back to work. Taking seriously the analytic writers who relate reading inhibition to a defense against learning about sexual matters (e.g., Fenichel, 1945), when he raised this issue, I decided to give him advice. "Don't try to read professional writings or even good literature. Forget about it for now. I want you to buy a copy of Playboy and try to read it, and we'll talk about your difficulties.”

It turned out he had never read Playboy, and all his life had always read only what was highly thought of. He protested my lousy taste and how awful the magazine was. I insisted he try to read it and talk about his difficulties, without explaining my choice of material. Within a few sessions, he was able to read it, while protesting all the while that it was a terrible, "pandering” magazine. While throughout the therapy, I always emphasize the importance of being able to think about anything, what seemed to make a difference was having an authority figure tell him to read sexy material, and being able to continually denounce it, and denounce my poor taste in suggesting it, and talk about the sexual ideas that came to mind. I, of course, talked about the normality of sexual curiosity and interest. After being able to read one issue, he discovered he could read ordinary books and his professional reading without trouble.

As we worked, he recalled more of his childhood. His mother, whom he idealized, used to dress him in white clothes when he was around five years old and send him out to play and then punish him for getting dirty. He felt that was all right because it was his fault. Of course, any parent knows that if you put a little boy in all white clothes in a hermetically sealed room, he would still manage to get dirty in half an hour or less. I pointed out how his mother set him up for this, that any child would get dirty, and that she probably enjoyed punishing him. He got mad at me, as most patients do when you make uncharitable comments about their parents. They often defend their parents by admitting defects that they earlier denied but which are less derogatory than your suggestions; at which point, I usually tell them they are right and I am wrong, unless they leave out something that is not speculation, but facts that they already know.

Although the patient and his family were Jewish, they lived in an Italian neighborhood in New York City. His mother, ostensibly for his safety, told him to go out and play, but not to play with those Italian kids because they are very dangerous. Of course, in an Italian neighborhood in New York City all the kids are Italian, and this advice prevented him from having friends.

All his life, he had wanted his parents' approval, and made extraordinary efforts to gain it, but nothing was enough. His parents continually cut him and his brother down. His older brother was a businessman, and when they talked to his brother, the parents talked about how brilliant Mr. X was and, when Mr. X published, what he had published. When his parents talked to Mr. X, they only talked about how much money his brother made and how little he did. Of course, his parents were neither brilliant nor wealthy, but they could always make their sons feel 
inadequate instead of feeling inadequate themselves. It was necessary to point out that both he and his brother were unusually bright and competent, but that time is limited and there is not time enough to do everything. If you decide to become a businessman, you are not going to write or get a Ph.D. If you become an academic you will write and get a Ph.D., but you're not going to make a lot of money. There just isn't time to do everything, but to do either one is an achievement.

This is particularly relevant because his psychotic break came when he finished his Ph.D. He had the fantasy that this would finally earn him the love and respect of his parents. He started teaching while completing his dissertation. When he finally finished, he was given a promotion, a raise, and tenure. He had finally done it. He called his parents to tell them the good news. They did not react. His father only asked him how much he was making. He told them he was getting a raise. Their response was that they were telling people he made more than that already.

From that point, his defenses unraveled until he was finally psychotic. Medication could not replace the triumph through acceptance that never would be.

\section{THERAPY MONITORING AND USE OF FEEDBACK INFORMATION FOR FIRST PART OF THERAPY}

Obviously, the improvement in his symptoms was the most relevant feedback that we were on the right track. As in any psychoanalytic treatment the feedback is the content of every hour.

Thus, for example, one of his initial terrifying hallucinations was burning in hell. This was not a verbal or abstract thought, nor a fear of eventual punishment. It was a horrible and apparently real experience.

The friend who had first referred him for treatment asked me if he had ever talked about the scar on his hand and suggested I ask him about it. When I asked the patient whether he had a scar on his hand, he told me that he did, and there was a story his mother told about the scar. According to her, they were in a store when he was a five. She saw him with a toy in his hand, and asked him where he had gotten it. He said a lady had given it to him. She asked the lady, who had not given it to him. His mother made him put it back and apologize to the lady. Then she took him by the hand, walked him home (four or five blocks), up the stairs to the third floor to their apartment, turned on a gas burner, and held his hand in the burner to teach him not to steal. The burn left a permanent scar. However, he maintained that it had no effect on him because he could not remember it.

I told him that I had a different opinion, that what you cannot remember has the most profound effect on you. I added further: "Most of us can only imagine what it would be like to burn in Hell. But you've actually been there.”

Even correct interpretations do not always lead to dramatic improvement. This one did. His hallucination of burning in Hell disappeared after that session. 
Early in his treatment, as he began to improve, he began to interact with people again. However, at a social gathering a physician told him that he was killing himself by seeing a psychologist, and that he should stop immediately and see a psychiatrist if he wanted to get any help at all. This set him back abruptly. His symptoms got considerably worse, and we had to spend weeks to work through the meaning of this encounter and the feelings of inevitable doom it produced, relating it not only to the present situation and the physician's lack of knowledge, but to the bad advice his mother regularly gave him, and that he needed to learn to trust his own experience, especially his own experience with people outside the family. Interestingly enough, a year later that physician developed a psychotic depression and called for help to a psychoanalytic psychiatrist in New York, who then referred the physician to the Chair of Psychiatry at the best medical school in the state, who then made a referral to a psychologist in the local area. The Chair said that he did not like referring to psychologists, but this one had done her internship in his department and was a remarkable therapist and the only professional in our local area he would trust. This psychologist, who for personal reasons was at that time confining her practice to evaluations, in turn referred the physician to me. The physician recovered with therapy. I resisted with difficulty the temptation to tell the physician how destructive that conversation had been to my patient, or even to mention that I knew of that conversation. (Of course, I did not mention the physician's symptoms or treatment to Mr. X.)

When it was time for the patient to go back to work, six months after he began treatment, it was possible to schedule an appointment just before his first class. Needless to say he was scared, but we talked about it. We then walked to his class, and I waited outside the classroom until it was over. He said, "It was OK," and I left and saw him at his next appointment the next day.

Several months later he reported that his colleagues said to him, "You're not still seeing that guy, are you? You're the healthiest guy in this department.”

"You know how sick I am.”

"Yes, I know how sick you are, but they may be right anyway."

Even though he never kept his hospitalization or diagnosis or psychoanalytic treatment a secret, he has been offered the chairmanship of his department several times in the ensuing years. He turned it down each time because he would rather be a scholar than an administrator. He also has had an extremely helpful effect on students. "You don't have to suffer like that," he has told students with problems. "There are competent people out there who can help you. I know. I really know. I was schizophrenic. And if I can get help, you can get help.”

They do not believe he was ever schizophrenic, but he assures them that he really was, and "If I could get help, you can get help." 


\title{
6B. COURSE OF THERAPY (CONTINUED)
}

\author{
The Move Towards Traditional Psychoanalytic \\ Psychotherapy with Broadening Interests
}

A year after treatment began, I could say to him: "Anyone can go crazy under enough stress, but under the stresses of ordinary life, you will never be psychotic again." He said, "This is better than I have ever been, better than what I used to call normality, but if you think this is good enough for me, you're crazy."

The treatment process then became more traditional. We moved to a couch and I sat behind him when it seemed more useful. (The relevant criterion for doing this is when the therapist and the patient believe that greater ambiguity and more dramatic transferences would be more likely to lead to useful material, rather than leading to less useful material, or even to retraumatizing the patient.) In his third year, Mr. X startled me by saying, "I have a book to write and I can't. Is that something that you can help me with?" Somewhat dubiously, I said, "People do go into analysis for writer's block." We spent most of a year on it, and he wrote that book. He has written several since. Others in his field have told me, however, that his professional reputation is based on that first book, now considered a classic in his field. Obviously it was well worth a year's analytic work. He knew that, even if I did not.

In his pre-psychotic period, he had never eaten a meal without nausea. When eating in a restaurant he would ask his wife, "Is it safe to eat this?" But he made progress. After years of treatment, he returned from a professional meeting in San Francisco to tell me how good the food was. He gave me the name of several restaurants.

"They're not like the places you recommend. You have to spend money there. But the food is magnificent."

He returned from a trip to France and recounted with tears in his eyes, "I can't tell you what French cooking is like. There is nothing like it in the United States." I knew we had made a lot of progress.

He reported with guilt his getting cable TV just so he could watch professional football. Both he and his son would watch together.

He showed even more guilt when he got a kitten and reported liking it. His parents disapproved of any animals in the house. They said animals were dirty and no reasonable person would let a dog or a cat live with them. Remember, he thought his parents were reasonable. But his wife wanted a cat, and with misgivings he went along with her, only to discover as almost all pet owners do, that their lives are better. It was with great shame that he reported that, when his cat fell from a tree and broke its leg, he paid a \$40 (in the 1960s) veterinarian fee to get its injuries attended to. "Of course you did; he is your friend," I said. His parents of course would have disapproved. 
This patient saw me for 14 years, although it was on a once-per-week basis after the third year. He kept raising new issues.

He went through psychosomatic problems. At one point his upper lip became swollen for no apparent reason. He described a horrible hallucinatory experience that had occurred even this late in therapy. He didn't know what it was. Something big and white. He couldn't see it clearly. Then it was close, it felt good, it was in his mouth. But then he couldn't breathe. It was awful. He couldn't get loose or breathe. It did stop, but it didn't feel like it would. I had to interpret the obvious: This was his mother's breast which felt good, but almost smothered him. She didn't seem to know enough to make sure he could breathe. It felt like she nearly killed him and might the next time. The hallucination disappeared. And the lip swelling disappeared shortly afterwards. Now by hindsight we might think of it as a summary of his relation with his mother, but I did not think of it that way at the time.

He had a heart attack. I visited him in the hospital. He wanted to know if his heart attack was emotional in origin. I talked to his cardiologist and his internist. When I visited the hospital, the nurses asked me if I would meet with them to talk about how they should relate to heart patients because they weren't getting help. I agreed, and we met in a group, where primarily they shared with each other what they knew and their experiences of such patients. They knew more than I did, but seemed to need permission to take what they knew seriously.

I told the patient I would like his permission to get a consult with a medical psychoanalyst who would know more about heart attacks than I did. "That sounds like a good idea. What the hell do you know about heart attacks?” My consultant suggested that I encourage the patient to find out everything he could about the physical factors, and that we should review the possible emotional factors thoroughly, and we might figure it out, or we might never be sure. I relayed the advice to the patient and we reviewed everything, but we never did become sure. He reviewed all the physical factors as well, took an active attitude towards his treatment and rehabilitation, and did not become a cardiac neurotic. He did come in angry several times when he asked his physicians why they were not doing the proper tests, according to his reading, and they agreed that he was right. "I'm no doctor, why should I be telling them what to do. They should know." But his realistic anger and his ability to act intelligently on his own behalf was helpful. Interestingly enough, he has not had a second attack.

As a child, he had taken piano lessons and, as usual, worked his heart out to gain his parents' approval and eventually developed some skill at classical piano. His brother had not done well, so the teacher decided to not try to teach him much but instead taught him a couple of popular tunes. Ready for appreciation of his hard work and the skill that the piano teacher seemed to find, the patient played for his parents, only to discover that his parents did not like classical music, but they were interested in his brother's popular piano tunes. This was just another example of hard work, apparent success, and what seemed to him to be subsequent failure, that is, realistic success which was not appreciated by his parents, so it failed to win him the approval he so desperately wanted.

In therapy, he decided to take piano lessons. 
"My wife isn't interested, and my kid doesn't like it, but I like it. I'm not going to bother them, I'll do it where they can't hear it, but I like it, and I am going to do it."

Eventually, he developed an interest in opera. "I know it's the lowest form of classical music, but I like it." This eventually led him to an interest in the local opera society. For years, he helped them by giving several free lectures around town before each opera presentation, with the help of a singer and pianist. He has helped create an appreciative audience for the opera guild productions.

Later, he began offering a general education course on opera at the University, which students very much liked. It was, of course, a labor of love, and undergraduate students tell me that they learned more about psychoanalysis in his discussions of the stories of operas than in their psychology courses. And he made both psychoanalysis and opera sound fascinating to them.

\section{The Treatment of His Wife and Marital Problems.}

Mr. X. also had marital problems.

I could leave her. There are bright, attractive, interesting women out there, but it would devastate her. When I needed her, she saved my life. The doctors said, "Shock him.” My family said, "Shock him.” People in your department said, "Shock him,” but she had the courage to defy them and see that I got real treatment. And I just can't do that to her.

But as we talked about his marital problems, he finally had the courage to tell her that when they made love, he felt like a rapist. She then said, "I never told you this. I was once raped." A trusted relative had set her up on a blind date with an older man who took her to a secluded place and raped her.

Mr. X said to me that he wanted her to get therapy, and that she wanted therapy. "I want her to get good therapy, and I do not trust the professionals in this town. Will you please see her." We discussed whether that would be upsetting to him, but he insisted that it would not be, and he would feel better knowing she was getting competent help.

I agreed to see her, and she told me more. Not only was she raped once, but when her mother tried to arrange an abortion, the obstetrician/gynecologist told her he would abort her if she had sex with him on the obstetric table. Her mother and the nurse were on the other side of the office door. Terrified, she agreed, and when he finished, he called her a whore and said he would never do anything as unethical as abortion. This second rape was more traumatic than the first. She eventually got an abortion. Years later, she heard that the obstetrician who performed the abortion safely and for a reasonable fee was jailed for a later abortion.

Despite my patient's urgings, it became clear that my seeing his wife was causing problems in the treatment for both of them. His treatment was slowing down. Material about being treated for someone else's benefit kept coming up, but discussion of it did not seem to help. I sought consultation, which helped me undo my mistake. I referred her to the nearest analyst of any competence, 40 miles away. She was sad and angry at me for that decision, but we talked about it, and she followed through and got real help. Her husband also got angry at me, but it 
was clear that afterwards both treatments were much better.

She developed breast cancer, and had one breast removed. Because the hospital would not trouble the cancer surgeon on the weekend, when she developed a pulmonary infection postoperatively, they did not treat it with antibiotics for three days, and she still suffers from complications to her breathing.

He said the surgery and her lack of a breast did not bother him. But he got interested in another woman. His wife learned of it, and luckily was still in therapy. He said she told him that maybe he was working through something, but she would give him three months. If it wasn't over by then, their marriage was. While initially angered, he began to bring up material indicating that the scars and absent breast were horrible and scared him, and his associations led to his own fear of castration, that is, literal fantasies of being mutilated and castrated. Long before the three months were up, he had given up his interest in the other woman, because he realized how much he really liked and admired his wife.

When she got her Ph.D., she was hired by the University. She became interested in methods of teaching and taught well. He talked about being guilty because he was not a good teacher, because he did not live up to her views on what a good teacher does. Of course, he was an excellent teacher, but he needed me to point out that there are many ways of teaching, that his wife knew one, which worked very well for her, but that he was also a good teacher, and there was no reason to change or to have to do things her way. Of course, the transference from his mother had to be pointed out.

\section{The Final Years: Work on His Relationship With His Son}

He described his need for the last two years of treatment: "I have a teenaged son. When he was a kid, he had a psychotic father. That was a hell of a thing to do to a kid. And I need help in undoing the harm I did him."

He and his son shared an interest in spectator sports -- football and basketball. While he had been anything but athletic in his younger years, he had often shared a fantasy with me of wishing he could be a professional football player, a defensive lineman -- Alex Karras - who, in addition to being a very funny man, was a very good football player. He was disappointed with his son, who refused to go out for high school football as a freshman, and he felt that the son would be a weakling like him. The son was neither tall enough nor agile enough for basketball to be an issue. The same medical analyst who had helped me with dealing with his heart attacks pointed out to me that high school football was a medical risk and his son was being rational and he should support his son's decision. It was helpful to him to think about it that way.

His son was having academic problems, despite having two parents who were college professors. As we talked, it became clear that the patient was terrified that his son would have the same problems in life he had. To save his son, he withdrew and did not share most of his life and thoughts with his son. He did not allow the son to identify with him, for fear of his son going through the hell he had gone through. He had to become aware of this fearful withdrawal from his son and to learn to not hold back, but to share all the good things in life that he knew 
about and enjoyed. The boy straightened out, went on to college, earned a Masters degree and had a successful career. When his son had a child, the patient was afraid his son would not be able to relate to the child, but both he and his wife were delighted to discover how well their child was relating to his infant son, their grandson.

\section{CONCLUDING EVALUATION OF THE THERAPY'S PROCESS AND OUTCOME}

The patient is now internationally renowned in his field. He is an outstanding scholar and teacher, as well as a good husband and father. His therapy did not make him a bright man or a kind man, but it did keep his brightness and kindness from being destroyed. It did allow him to feel safe, perceive and think realistically and creatively, and use his intelligence and kindness to make his own and other people's lives more interesting.

A few years ago (more than 20 years after the completion of treatment) the patient sent me a copy of a magazine article about a prestigious award that he had received with a note saying that he had never properly thanked me for giving him back a life. Remembering the role of his parents never acknowledging his achievements had in producing his problems, I wrote back that, "From time to time I have heard from people in your field about your accomplishments and from your students about your teaching, and it has always been a source of satisfaction that I was available when you needed me."

\section{REFERENCES}

American Psychiatric Association (2000). Diagnostic and Statistical Manual of Mental Disorders, Fourth Edition, Text Revision. Washington, DC: American Psychiatric Association.

Breggin, P. R., \& Cohen, D. (1999). Your Drug May Be Your Problem. Cambridge, MA: Perseus.

Deikman, A. J., \& Whitaker, L. C. (1979). Humanizing a psychiatric ward: Changing from drugs to psychotherapy. Psychotherapy: Theory, Research, and Practice, 16, 204-214.

Dorman, D. (2003). Dante's Cure. New York: Other Press.

Fenichel, O. (1945). The Psychoanalytic Theory of Neurosis. New York: Norton.

Fromm-Reichmann, F. (1947). Transference problems in schizophrenia. In S. S. Tomkins (Ed.), Contemporary Psychopathology (pp. 371-380). Cambridge, MA: Harvard University Press.

Greenberg, J. (1964). I Never Promised You a Rose Garden. New York: Holt, Rinehart, and Winston.

ISPS-US (2006). Web site of the United States Chapter of the International Society for the Psychological Treatments of Schizophrenia and Other Psychoses: http://www.isps-us.org/

Jackson, G. E. (2005). Rethinking psychiatric drugs: A guide for informed consent. Bloomington, IN: AuthorHouse.

Joseph, J. (2004). Schizophrenia and heredity: why the emperor has no genes. In J. Read, L. R. Mosher, \& R. P. Bentall (Eds.), Models of Madness: Psychological, Social, and Biological Approaches to Schizophrenia (pp. 67-84). Hove and New York: Brunner- 
Routledge.

Karon, B. P. (1960). A clinical note on the significance of an "oral" trauma. Journal of Abnormal and Social Psychology, 61, 480-491.

Karon, B. P. (1994). Effective Psychoanalytic Therapy of Schizophrenia and Other Severe Disorders (videotape and supporting written material). The APA Psychotherapy Videotape Series. Washington, D.C.: American Psychological Association.

Karon, B. P. (2003). The tragedy of schizophrenia without psychotherapy. The Journal of the American Academy of Psychoanalysis and Dynamic Psychiatry, 31, 89-118.

Karon, B. P. (2005). Recurrent psychotic depression is treatable by psychoanalytic therapy without medication. Ethical Human Psychology and Psychiatry, 6, 45-56.

Karon, B. P. (in press). Karon's Pathogenesis Index. In S. R. Jenkins (Ed.), Empirically Validated Scoring Scales for the Thematic Apperception Test.

Karon, B. P., \& VandenBos, G. R. (1972). The consequences of psychotherapy for schizophrenic patients. Psychotherapy: Theory, Research \& Practice, 9, 111-119.

Karon, B. P., \& VandenBos, G. R. (1981). Psychotherapy of Schizophrenia: The Treatment of Choice. New York: Aronson. (Blue Ridge Summit, PA: Rowman \& Littlefield Edition).

Karon, B. P., \& Widener, A. J. (1994). Is there really a schizophrenogenic parent? Psychoanalytic Psychology, 11, 47-61.

Ratner, S. G., Karon, B. P., VandenBos, G. R., \& Denny, M. R. (1981). The adaptive significance of the catatonic stupor in humans and animals from an evolutionary perspective. Academic Psychology Bulletin, 3, 273-279.

Read, J., Goodman, L., Morrison, A. P., Ross, C. A., \& Aderhold, V. (2004). Childhood trauma, loss, and stress. In J. Read, L. R. Mosher, \& R. P. Bentall (Eds.), Models of Madness: Psychological, Social, and Biological Approaches to Schizophrenia (pp. 223252). Hove and New York: Brunner-Routledge.

Read, J., Mosher, L. R., \& Bentall, R. P. (Eds.). (2004). Models of Madness: Psychological, Social, and Biological Approaches to Schizophrenia. Hove and New York: BrunnerRoutledge.

Read. J., \& Ross, C. A. (2003). Psychological trauma and psychosis: Another reason why people diagnosed schizophrenic must be offered psychological therapies. The Journal of the American Academy of Psychoanalysis and Dynamic Psychiatry, 31, 247-268.

Read, J., Seymour, F., \& Mosher, L. R. (2004). Unhappy families. In J. Read, L. R. Mosher, \& R. P. Bentall (Eds.), Models of Madness: Psychological, Social, and Biological Approaches to Schizophrenia (pp. 253-268). Hove and New York: Brunner-Routledge.

Silver, A. S., \& Larsen, T. K. (eds.) (2003). Special Issue: The Schizophrenic Person and the Benefits of the Psychotherapies - Seeking a PORT in the Storm. The Journal of the American Academy of Psychoanalysis and Dynamic Psychiatry, 31(1).

Strean, H. S., \& Freeman, L. (1990). The Severed Soul. New York: St. Martin's Press.

Teixeira, M. (1992). Psychoanalytic theory and therapy in the treatment of manic-depressive disorders. Psychoanalysis and Psychotherapy, 11, 81-96.

Whitaker, R. (2002). Mad in America. Cambridge, MA: Perseus. 